\title{
"Hunger Hurts But Starving Works": A Case Study of Gendered Practices IN THE ONLINE PRO-EATING-DISORDER Community $^{1}$
}

\author{
KRISTA WhiteHEAD
}

\begin{abstract}
This paper investigates collective identity-work of Pro-eating disorder (Pro-ED) groups on the Internet. Using an adaptation of face-to-face ethnographic methods to investigate online communication (Mann and Stewart 2000), the author analyzes five collective organizing practices in Pro-ED groups that reveal a highly gendered character: 1) promoting surreptitiousness, 2) organizing in and around the realm of domesticity, 3) equating beauty with self-worth, 4) relying on friendship as a chief organizing principle, and 5) using fandom as a method of attracting and maintaining members. In spite of exceptional resistance to their activities, women in the Pro-ED community are able to achieve a collective Pro-ED identity wherein they maintain eating-disordered lifestyles. The case study presented here is counter to popular sociological understandings of collective identity mobilization as having categorically positive consequences for its members.
\end{abstract}

Keywords: pro-eating disorder; pro-ana; pro-mia; collective identity; gender; social movements; identity formation

Résumé : Cet article traite des travaux sur l'identité collective sur Internet des groupes PRO-manger souffrant de troubles de l'alimentation (Pro-ED). En utilisant une adaptation des méthodes ethnographiques face à face pour examiner la communication en ligne (Mann and Stewart 2000), l'auteur analyse cinq pratiques organisationnelles collectives des groupes Pro-ED qui révèlent un caractère qui tient fortement compte du rôle des hommes et des femmes : 1) la promotion de la clandestinité, 2) une organisation relevant du domaine de la domesticité, 3) l'assimilation de beauté à confiance en soi, 4) le besoin d'amitié comme principal principe organisationnel et 5) l'utilisation de fans comme méthode d'attirer et de conserver des membres. Malgré une résistance exceptionnelle à leurs activités,

1. Acknowledgements: This article would not have been possible without the thoughtful guidance, encouragement, and direction of Judith Taylor, Adam Green, and Bonnie Fox. The author would also like to thank the graduate student members of a sociology $\mathrm{PhD}$ seminar with whom this paper began. The anonymous reviewers at $C J S$ provided useful and thoughtful suggestions that improved the final version of this paper. 
les femmes de la communauté Pro-ED sont en mesure d'arriver à une identité collective Pro-ED où elles conservent des styles de vie marqués par des troubles de l'alimentation. L'étude de cas qui est présentée ici s'éloigne des connaissances sociologiques populaires de la mobilisation de l'identité collective comme ayant des conséquences formellement positives pour ses membres.

Mots-clé : Trouble de l'alimentation pro-manger; pro-ana; pro-mia; identité collective; sexe; mouvements sociaux; formation d'identité

Anorexia is not only about food. It becomes a mechanism to cope with serious, emotional problems. My wounds will never heal. I have not been able to recover. Anorexia kills, but as controversial as it may be, it keeps me alive. (Anna on Pro-ana

[DOT] US website, November 2006).

Starvation is a great motivation. I stare in the mirror and I think I look bigger. Is she my soul friend or my enemy? The answer is that you cannot answer, because ana (anorexia) endures my life. I step on the scales and ana (anorexia) tells me I'm failing but it's not true, or is it? (personal homepage linked to Pro-ana [DOT] US website, November 2006).

I am so glad to find someone/something that supports me, and my decision to be perfectly skinny. Why's everyone always trying to fight us? (Guestbook, Pro-ana [DOT] US website, January

2007).

\section{INTRODUCTION}

The above narratives of women's struggles living with anorexia are emblematic of those found online in the Pro-eating disorder (Pro-ED) community. Online Pro-ED communities promote the idea that eating disorders are not diseases or illnesses, but rather represent lifestyle choices. Research on Pro-ED websites indicates that participation in proanorexic behaviour is facilitated, encouraged and supported via the Internet (Abbate et al. 2006; Tierney 2006), whereby individuals exchange tips with respect to how to maintain their behaviours. In online discussion forums, blogs, and personal homepages women routinely reflect on and discuss their reliance on the very eating disorders that they know could kill them. Purveyors of the sites express their gratitude for the support provided in the community, and promote a "safe" eating-disordered environment. Women discuss their struggles, which include obsessions with food, dieting, bingeing, purging, weighing, exercising, and counting calories, among others. Site moderators and administrators of online Pro-ED groups have registered over one million users per week on some of their websites (Pro Ana [DOT] US Homepage, December 2008). 
The high-risk nature of the Pro-ED community has led to popular interest in its activities. Journalistic examinations of the community have emphasized the "dangerous," "deadly," and "destructive" quality of the websites, leading to the stigmatization of the community as whole (for examples see Depowski and Hart 2006; Eaton 2006). The mainstream media believes that the proliferation of such sites promotes a destructive lifestyle, which needs to be stopped.

Despite such resistance, however, members of online Pro-ED groups have built a meaningful community around their eating-disordered lives. Notwithstanding members' self-declared position as a "community" or "movement" sociologists have overlooked the collective identity-work that takes place among members online (but see Day and Keys 2008). The life-threatening activities that are promoted among women in the community distract scholars from noticing the work that members invest into cultivating, maintaining, and sustaining their collective identity as "Pro-ED's." However, it is this very work that allows members to preserve their eating-disordered lifestyles. Thus, it is this collective identitywork that is the focus of the present paper.

With respect to online Pro-ED communities I ask the following questions: How do women involved in Pro-ED communities organize online? What for? And what allows them to achieve such organizing? In answering these questions, I illustrate that despite widespread disapproval of their activities, Pro-ED members are able to maintain self-destructive, "safe" 2 eating-disordered lifestyles. They are able to do so by drawing on five highly gendered strategies. Pointing to the gendered character of Pro-ED community practices identifies gender as the mechanism through which a damaging, yet collective way of being is legitimated and sustained by its members. The findings of the present case study contribute to social movement research by countering romantic versions of collective-identity mobilization as having categorically positive consequences for its members (i.e., liberation or social change). With this insight in mind we are able to ask new questions with respect to our understanding of collective-identity organizing altogether.

\section{Social Movements, Collective Identity, ANd Gender}

Recently collective identity has become a core concept in social movements literature. At the same time, however, collective identity is difficult to define. Some scholars see it as a process (see for example Melucci

2. Pro-ED members frequently reiterate the importance of engaging in "safe" eating disordered practices. Their notion of safety, what it involves, and how it is achieved, is discussed more fully in another section of this article. 
1995), while others see it as an end product or achievement. Drawing on both perspectives, Hunt and Benford (2004:447) define collective identity as "a cultural representation, a set of shared meanings that are produced and reproduced, negotiated and renegotiated, in the interactions of individuals embedded in particular sociocultural contexts." Investigating the cultivation, production, and achievement of collective identity in different sociocultural contexts, such as the Pro-ED community, provides a deep, rich understanding of a concept that is often reified.

Despite divergence in some definitions, scholars of social movements agree that the concept of collective identity has changed the way we see the field. New social movement theory (NSMT) has extended our conceptualization of collective action to include groups of individuals who organize around specific identities rather than organizing for institutional reform (Polletta and Jasper 2001). Contemporary research in social movements no longer excludes identity-centred groups from analyses of mobilization, but often considers the construction of identity as an outcome of collective organizing (Taylor 1996; Taylor and Whittier 1992). In some cases, identity-centred claims are considered a protest strategy in and of themselves (Bernstein 1997; Polletta and Jasper 2001).

The achievement of a collective identity occurs through various processes of exclusion, solidarity, support, and boundary maintenance (Taylor 1996; Gamson 1997; Polletta and Jasper 2001). Models of collective behaviour informed by resource mobilization and political process theories rely heavily on the idea that movement adherents make rational choices with respect to their strategic actions. In challenging this assumption, however, we have come to realize that movement members often choose tactics that reflect "who we are" as feminists, animal rights activists, or environmentalists for example (Polletta and Jasper 2001). Collective identity as a movement strategy can therefore reflect adherents' expressive motivations and not simply their rational calculations.

Demonstrating how collective-identity organizing is gendered has helped us understand the cultural impetus behind members' expressive motivations. Collective identity organizing that occurs within a gendered framework can both subvert gender ideologies and reinscribe them. Sometimes they do both (Taylor 1996; Fonow 1998). Research focused on the gendered character of collective identity organizing attempts to make the gender ideologies that inform organizing more transparent while also clarifying the processes that inform collective mobilization (see for example: McAdam 1992; Taylor 1996; Ferree and Merrill 2000; Hercus 2005). We learn a great deal about collective mobilization by treating gender as an important analytic "variable" in and of itself. An important example of such work is Verta Taylor's (1996) investigation of 
the women's self-help movement, feminism, and postpartum depression. She challenges traditional social movement theory by arguing that a group of women organizing around their experience and identity, whose behaviour and group activities were previously identified as apolitical, were in fact engaged in overt political, social, and cultural protest (1996). Gendering collective mobilization has led to important insights with respect to social movement behaviour more generally. For example, we no longer consider state centred protest as the only legitimate form of collective resistance (Taylor 1996), nor do we exclude identity centred protest from our analyses (Armstrong 2002).

Although a great deal has been learned about collective identity, many questions have been left unanswered. We still do not know about the "cultural building blocks," which are used to cultivate collective identities (Polletta and Jasper 2001). That is, we need to understand the components of culture that contribute to the construction of collective identities. Further, we need to see, beyond laws and political status, "what are other tools and raw materials of identity work?" (Polletta and Jasper 2001:299). Social movement scholars are familiar with cases of collective identity mobilization where members' collective identity organizing produces, or attempts to produce, liberatory results for its members (gay and lesbian rights groups, self-help groups, women's movements, etc.). We know less about groups who organize around and for collective identities that do not produce results related to social change or liberation, such as the group analyzed in the present case study.

This piece answers Jasper and Poletta's call to investigate the "cultural building blocks" and "tools" that are used to build collective identity (2001), while also offering an excellent sociocultural context within which to explore collective identity mobilization that does not seek to, or produce liberation - in the traditional sense of the term - for its members. In spite of exceptional resistance to their activities, women in the Pro-ED community are able to maintain eating-disordered lifestyles. I argue that they do so with the use of five highly gendered practices. Their accomplishment confounds popular sociological understandings of collective identity mobilization as undoubtedly beneficial for its members to reveal the destructive yet significant possibilities that can exist in community contexts. Identifying gender as a tool through which women in the Pro-ED community cultivate a collective identity serves an example of how women often rely on gendered principles to rationalize a set of behaviours that are damaging. The findings of this case study extend social movement research by challenging the flawed assumption that sees collective identity mobilization as a stepping stone for social change and/or liberation. 


\section{Case, Methods, and Methodology}

Single cases studies are often conceptualized as "bounded" units studying them can be important in their own right in the absence of comparison to other cases (Stake 1994:236). Sociological knowledge is often gained from single-site case studies (Walton 1992), whereby such case studies interrupt generalizations, support existing findings, introduce new questions, and propose new avenues for research (Goodwin and Horowitz 2002; Lieberson 1992).

The data used for this case study is derived from a "virtual ethnography" (Hine 2000) of the Pro-ED community. In September 2006 I began informally exploring the community by investigating their presence online. In Internet speak, I googled the terms "pro-ana" and "promia" (pro-anorexic and pro-bulimic respectively). A site that identified with both terms pro-ana and pro-mia, called "Pro Ana [DOT] US" (hereinafter PADU) was used as the central source of data for this study. Upon discovery of PADU, I visited the site on a daily basis for approximately one to three hours at a time for a six-month duration until February 2007.

The daily visits to the site are rooted in an adaptation of face-to-face ethnographic methods designed for investigation of online communication (Mann and Stewart 2000). By definition, an ethnographer attempts to immerse her/himself into the environment being studied. Visiting the sites on a daily basis, therefore, approximated the visiting habits of individuals most involved in the sites' production and maintenance. Much like individuals who check their email everyday, Pro-ED adherents check the Pro-ED sites on a daily basis, and often have free email accounts associated with the websites. My daily visits made use of links on the site to keep track of the changes and updates that occurred. In the first two weeks of my analysis I explored all sections of the website to get a sense of the overall online environment; however, not all my visits over the course of the six-month period explored every section of the website. Instead I kept an archive on the data on the site in a separate document in the event that the website content was modified or taken offline. I took descriptive fieldnotes in the process of visiting the sites in order to maintain a record of my observations. My daily visits indicated that the site was active, regularly featuring new posts and ongoing dialogues. PADU provided links to outside sites with similar beliefs about eating disorders. These sites, administered by individuals and/or teams, are intended as vehicles to elicit conversation among people with converging understandings of eating disorders.

I used PADU as a central source of data for this study for logistical reasons directly related to the timing of the study and public reaction 
to the presence of such sites. Over the course of the study many other Pro-ED websites were dismantled, possibly as a result of their controversial subject matter. Mainstream coverage of the websites took hard lines with the websites content, initiating debates around censorship and free speech. This study was conducted during a very precarious time in the "life" of eating disorder websites during which Internet servers wrestled with the idea of shutting many of the sites down. PADU was one the few sites that remained extremely active over the course of the study. Since then, Pro-ED groups have further proliferated online, now featuring pages on social networking sites such as "Facebook" and "MySpace."

All the data (written material and photographs) gathered for the present case study is - or was at the time of the study - publicly available on the Internet. I did not become a member of any of the websites nor did I announce my presence to the community. I sought to capture the community in its "natural habitat" and announcing my presence could have affected their habitual interactions and routines, also undermining the interpretive framework that guides this study. I only analyzed information that was publicly available online and was not under any expectation of privacy. The public availability of such information and its subsequent analysis conforms to the Tri-Council Policy Statement: Ethical Conduct for Research Involving Humans which states that "research about a living individual involved in the public arena, or about an artist based on publicly available information ... is not required to undergo ethics review" (Canadian Institutes of Health Research, Natural Sciences and Engineering Research Council of Canada, Social Sciences and Humanities Research Council of Canada, 1998, with 2000, 2002, and 2005 amendments). On the websites I visited, the statements, narratives, photos, and opinions of the members were under no expectation of privacy and were thus treated as public information. In fact, numerous sites I visited were personal homepages of women involved in the ProED community designed specifically for public viewing. Some sites had private chatrooms and message boards which I did not enter, nor did I participate in any communication that was assumed to be private.

Using a grounded theory approach ${ }^{3}$ to narrative analysis, I identify and analyze five dominant practices used by members in the online Pro-

3. A grounded theory approach to qualitative data is based on the coding and organizing of data into themes that involves conceptual ordering. The process of conceptual ordering may lead to the creation of distinct "analytical categories" which in turn might develop into "substantive theory" and then ideally to the construction of "formal theory" (Glaser and Strauss, 1967; Strauss and Corbin, 1998). I systematically coded the websites for answers to the following questions: How do women in the Pro-ED community organize online? How do they communicate with each other? What do they talk about? What information do they share? 
ED community: 1) promoting surreptitiousness, 2) organizing around the realm of domesticity, 3) equating beauty with self-worth, 4) fostering friendship among each other and their eating disorders, and 5) using fandom as a method of attracting and maintaining members. Further, I identify and analyze two processes in the Pro-ED community that help members display their collective identity: 1) creating boundaries; 2) developing group consciousness through new self-understandings.

Narrative analysis sees the social world as a "sociology of stories" where "[w]e are constantly writing the story of the world around us: its periods and places, its purposes and programmes, its people and plots. We invent identities for ourselves and others and locate ourselves in these imagined maps" (Plummer 1995: 20). In the tradition that narrative analysis is used (Epstein et al. 2000), personal narratives provide a means through which individuals assert selfhood and personhood to situate themselves in the broader social context thus affirming their subjectivities. Personal narratives represent a way in which people attempt to achieve legitimacy with others and themselves thereby constructing subjectivity.

The websites analyzed herein feature narratives (sometimes more aptly described as rants and musings, but nonetheless reflections on lived experiences) of Pro-ED community members. An investigation of these narratives gives us insight into the social world of those who associate with Pro-ED activities and behaviours and assert a Pro-ED identity. Together the comments, "rants," opinions, and journals posted online by Pro-ED adherents represent elements of their personal narratives that are used to enact their identity as "Pro-EDs." This identity is preserved by its members through the use of five highly gendered practices.

\section{Organizing on the Web: Displaying a Pro-Ed Collective Identity}

The Pro-ED community does not mobilize for social change, nor have members identified an opposition, however, they organize for solidarity, support, and encouragement. They state, "We are a group of people who suffer from eating disorders, trying to fill in the gap of solidarity" (PADU, December 2006). Despite not always challenging how they are represented, their statements implicitly argue for the right to resist treatment and maintain behaviours deemed unhealthy. Similar to individuals who challenge both the medicalization/de-medicalization and the common perceptions of their mood disorder, mental illness, gender identity, and sexual orientation, etc. (Allred 2009; Taylor 1996), Pro-ED community members are not satisfied to be seen as sick, unwell, and in need of treatment. 
However, on the whole the Pro-ED community achieves a collective identity and protects a set of practices upon which that identity relies. For Taylor (1996) collective identity represents a shared definition of a group that surrounds common interests, experiences, and solidarity. It is the result of three similar, interrelated processes: 1) the creation of boundaries (physical, psychological, or otherwise), 2) the development of a group consciousness revolving around the introduction of new selfunderstandings of the groups' problems and experiences, and 3) the politicization of what is commonly referred to as personal issues and problems (Taylor 1996:127-128). Two of these, discussed below, are evident in the online interactions between members of the Pro-ED community.

\section{Creating Boundaries}

Pro-ED adherents create boundaries in two distinct ways. First, PADU's introductory website features several warnings and disclaimers asserting that the website is for people who already have eating disorders, not for people hoping to "catch" one. The site warns:

PLEASE NOTE: All tips and tricks located on this page, are meant for people who already have Anorexia, or Bulimia, and who don't plan on stopping it. These are meant as safer practices, of Anorexia or Bulimia. This does not mean, "Oh I'm gonna become emaciated WHOOHOO. Because nobody cares if your $[s i c]$ thin when your $[s i c]$ dead, and tubes in your body isn't a good look. (PADU, October 2006)

This statement reflects the boundaries drawn between those who have eating disorders and those who are curious or would like to be thin. Those who do not have eating disorders are not welcome on the site. Moreover, the tone in which the statement is delivered represents a perilous aspect of having an eating disorder. The lack of proselytizing and promotion of the idea that eating disorders arise within the individual in seclusion suggests a naturalizing medicalized logic. The site administrator maintains that the site is

for people who already have Anorexia, or Bulimia, and want to MANAGE their disease as safely as possible, without recovery. Many of these people do not want recovery, they just want to get through their everyday lives. (PADU site administrator, 2006)

The site is designed and intended for people who recognize and identify themselves as individuals with eating disorders. In order to participate in the chat rooms and have open access to blogs and nightly conference calls one must become a member of the site. Becoming a member involves obtaining a PADU administered email address, as 
well as abiding to the rules of the website. Site administrators maintain: "We WILL NOT give out tips and tricks, and other dangerous advice to anyone" (PADU, Terms of Service, 2006). While site administrators insist that dangerous guidance and instruction are not provided on the website, there is an abundance of recommendations available through the site that are simply not labeled as such. This information is often available through other sites that are linked to PADU (i.e., members' personal homepages, or social networking profiles). Generally members are forthcoming about ways to curb, cope, and forget hunger. One member suggests, "If you are going to eat and there is really no stopping you then swallow two laxatives before and after eating" (personal homepage linked to PADU, October 2006).

Members further create boundaries in their community by denouncing the presence of individuals who attempt to fake eating disorders. The website administrators communicate updates to the site on a daily basis through the radio broadcasts where they encourage site members to disapprove the presence of "wana's" or "wananorexics" in the chatrooms, and nightly conferences calls facilitated by the site. Wana's are described as people who don't actually have eating disorders but who visit the website to obtain simple methods to lose weight quickly.

The Pro-ED community seeks to draw specific boundaries around those who have eating disorders and those who do not. In other words, they attempt to establish a bounded eating-disordered identity. Anna Robbins, the founder and main site administrator of PADU, points to some of the basic principles behind identifying who is and isn't anorexic or bulimic when she asserts that "the website is for people who already have eating disorders, not getting tips and tricks, we don't do that ... the site is not for diet seekers" (PADU News and Announcements, Episode \#2). Anna displays her disgust for "wana's" by stating,

wanorexic emails, I'm really getting sick of getting them..., if you're looking for a healthy way to lose weight an eating disorder is not the answer ... don't try to fake diseases that are going to haunt you for the rest of your life. (PADU News and Announcements, December 2006)

Drawing these boundaries reinforces the legitimacy and integrity the Pro-ED community associates with their collective Pro-ED stance. It also emphasizes the prestige and exclusivity associated with the practices, which, in the minds of participants, cannot and should not easily be conferred. To them, an eating disorder is an achievement. One site depicts a cartoon of a thin starlet accompanied by the caption "Nothing tastes as good as thin feels." The cartoon is followed by a list of tips for how to maintain one's resolve to not eat. These images and text convey 
an identity that requires constant vigilance to maintain, and that promises to those successful: euphoric self-satisfaction and comradeship in a unique and exclusive club. Like young girls who create secret clubs in high school where only "cool" girls can be members (Brown 2003; Simmons 2002), the Pro-ED community only wants members who are truly living an eating-disordered way of life. Distinguishing between "real" and "fake" anorexics and bulimics draws the necessary boundaries of credibility around the Pro-ED community. It ensures that outsiders do not simply see these women as crash dieters, but rather as women living with eating disorders. The community maintains that it wants to support and encourage its members, and defining authentic members helps achieve this support. "Wanorexics" are not tolerated. "To the bone" a website linked to PADU, states:

This is more then [sic] an obsession. It is our beautiful addiction and this is our community, here to help, support and encourage what we believe are achievements. I do not ask you to come here wanting cliché and petty advice, nor are you to use the term 'Eating Disorder' along with 'Crash Diet'. This is our lifestyle. This is our reality. And it isn't easy. (personal homepage linked to PADU, December 2006)

The creation of boundaries in communities attempting to assert a collective identity is well established (Taylor 1996; Taylor and Whittier 1992; Gamson 1997). The Pro-ED community is no exception to this observation. For Pro-ED adherents yo-yo dieters are not, and do not represent, the genuine Pro-ED lifestyle. The presence of diet seekers online means that the community is not being taken seriously and thus loses legitimacy. The Pro-ED community is asserting their collective identity not only for the benefit of outsiders and antagonists, but also to establish an order within their own community. This order legitimates the collective identity assertions that can be made by those who are truly a part of the community.

\section{Group Consciousness and Self-Understanding}

The development of new self-understanding is also apparent in the narratives offered by the members. The self-understanding espoused by the members revolves around how they conceptualize eating disorders both as friend and enemy and how they achieve community through the sites. The site administrators of PADU state, "Many of us here have an Eating disorder and are here for the sense of community. If you ever feel that you need someone to talk to please do, we are here for everyone" (PADU, December 2006). Members in the community understand the dangers associated with their eating disorders, yet openly discuss how they could 
not live without them. One member illustrates her dependence on her anorexia when she writes, "I can't live with ana but I defentially [sic] can't live without her. ana [sic] gives me hope and she helps me to cope. Thank you ana for being my inspiration" (personal homepage linked to PADU, October 2006). She recognizes that eating disorders are dangerous and destructive but the community also provides her with unconditional support and acceptance, helping her gain strength, legitimacy, and subjectivity from her eating disordered lifestyle.

By conceptualizing their eating disorders as friends, women in the community demonstrate dependence on their eating disorders to define their personhood. Members often recognize the health dangers associated with eating disorders, but maintain that without them they would be nothing. Thus, asserting a Pro-ED identity helps these women feel alive, creating subjectivity in the face of their struggles with dangerous behaviours. One member reports that "Ana loves me, She may use me, But she won't forget me. I am not her victim, I am one of her lovers. Everyday I pray to be loved above the rest. Perfect is what I need to be. Perfect one day I shall be" (personal homepage linked to PADU, October 2006). This member's narrative illustrates how she relies on her eating disorder to define her subjectivity through the indisputable love it provides for her. Moreover, she admits her dependence on her eating disorder online, knowing that she will receive unconditional understanding from other members.

Members' self-understanding relies heavily on their need to feel hungry, not eat, and be successful at starving themselves. One member maintains, "I'm hungry. Thank God" (personal homepage linked to PADU, October, 2006). Here being hungry is equated with being alive, and feeling worthy of living. She continues,

I never, ever want to eat again. I suppose that's a given, but I love teetering like this, always having to be wary of my weak body and always having to think twice to make sure I keep myself upright. Always the girl with the least food on her plate.... Walking the tight rope between two extremes (perhaps living and dying), safely removed from all of it. (personal homepage linked to PADU, October 2006)

This and similar expressions of the Pro-ED community's struggle with the dangers of the disorders, while also feeling a deep need and dependency on them, corroborate Dias' (2003) findings that members in the Pro-ED community find a "sanctuary" through their eating disorders and the support they receive from other nonjudgmental members in the Pro-ED community (Dias 2003). A guest to the PADU website states: "Wow, this site is so ... nice! Some sites don't have this kind 
of great supportive atmosphere where you can still feel in control. It's such a friendly site and it really helps just to be looking at the page with such positive comments and people" (PADU Guestbook, December 2006). Pro-ED members develop a group consciousness that involves nonjudgmental, unconditional support of each other. They understand that women in the community are dependent on their eating disorder to define their subjectivity. For all members, this dependence is fulfilling and meaningful. Moreover, their self-understanding of their identity as Pro-ED women is recognized as both dangerous and a method of retreat and requires that other members provide nonjudgmental support. Their self-understanding as accomplished anorexics and bulimics who both suffer and achieve refuge through their eating disorders, relies on the encouragement they receive from members of the community. This encouragement takes place within the context of five highly gendered practices discussed below.

\section{"Thin is In": The Gendered Practices of Collective-IDentity Cultivation in the Online Pro-ED Community}

Despite an absence of mobilizing for social change, the Pro-ED community provides support and encouragement to its members. Members achieve a collective identity and protect a set of practices upon which that identity relies by employing highly gendered strategies. These tactics are gendered in that they represent a highly feminized version of female gender identity.

Given the precarious nature of virtual reality communication and the identities espoused therein, it is impossible to uncover the actual demographic of Pro-ED community members in terms of its age, race, and class constituency. There is, however, a reasonable expectation among the research community that this group is primarily composed of white women (Dias 2003; Fox et al. 2005; Norris et al. 2006). Despite my own scholarly commitment to conduct intersectional analyses (i.e., examining the effects of intersections of race, class, and gender etc.) of social phenomena, the available data used in this study does not allow such an investigation.

\section{Promoting Surreptitiousness}

The surreptitious, secretive, and stealthy behaviours Pro-ED affiliates promote conform to popular conceptions of women as disingenuous and manipulative, preferring secrets to open communication, and achieving a sense of personal power through subterfuge (Simmons 2002; Brown 
2003). Women's association with stealth, secretive practices to obtain what they want has been documented (Kenny 2000; Stacey 1998).

Surreptitious behaviour is openly encouraged in the Pro-ED community. Participants rely on songs as accompaniments to their "thinspiration" videos (see below) and regularly employ the song "Courage" by Superchick. The lyrics make sense in the context of understanding women as manipulative and stealthy, especially with respect their eating habits. In this song, the woman describes how she hides her eating disorder by lying and keeping her illness a secret. The songwriter sings,

I told another lie today.

And I got through this day.

No one saw through my games.

I know the right words to say.

Like: "I don't feel well","I ate before I came."

(Courage by Superchick).

Such lyrics, promoting disingenuous social relations, are an emblem of the Pro-ED movement. The song, referenced in numerous journal entries, is an anthem for members. In addition, several "YouTube" videos featuring a Pro-ED stance play it in the background, indicating its resonance.

The promotion of surreptitious behavior in the Pro-ED community is further illustrated in the narratives of its members. Women routinely discuss the lengths they go to hide their disorder from their family, friends, and partners and request tips from other Pro-ED members. On one occasion, a frequent contributor to the dialogues, asked other members for tips about purging, revealing that she had too many calories in one day and could not seem to make herself throw up. She wrote:

Awwww, I was doing so well today nothing but an apple and a cup of juice. Until I came home and my mom made me eat. The damage: a massive bowl of spinach ravioli and a little cup of ice cream. And you know whats $[$ sic $]$ worse? I can't throw it up. I'm not sure why ... but it just won't come anymore. Any tips?? I could really use it right now. (PADU online post, October 2006)

Similarly, another member reminds the community about the importance of secrecy. She writes: "Make plenty of ana friends to help you through the difficult times. Make sure to hide your weight loss around people who would tell" (PADU online post, November 2006).

Members go to great lengths to hide their disorder from their parents, especially their mothers. Many women express resentment towards their mothers for making them eat, especially when they were doing well with 
their weight loss goals and fasting. One guest's post on PADU's online guestbook discussed her eating disorder and wrote:

I haven't eaten really anything in three days, except a bit of soup my mom forced into me (she thinks I have the flu) and a piece of cake I had to eat, but I managed to throw that up.... I feel kind of shaky and lightheaded, but other than that, really good! It'll be hard hiding this from my parents (they're pretty observant). (PADU, Guestbook, October 2006)

The website administrators indulge the questions they receive about members' need to maintain the secrecy of their eating disorders. In PADU'S "Frequently Asked Questions" section of the website, one of the questions asks, "Will you tell my parents?" (PADU). The question refers to whether the site administrators will reveal a young woman's membership on the site to her parents. The site replies:

NO WAY. You come here on your own volition. No one chooses your life but yourself. But take in mind, WE ARE NOT responsible for your actions. If you tell your parents, its your business, not ours. Please note, that we do not agree with younger people coming onto this site. It is discouraged, but we cannot monitor a million plus users a week. (PADU, FAQ Section, January 2007)

Administrators imply that they acknowledge the need for secrecy among eating-disordered women and encourage their necessarily secretive behaviours.

The photos displayed on the websites also attest to the surreptitious behaviour promoted by members in the Pro-ED community. The members themselves, with the use of mirrors, take the majority of their personal photos (see Figure 1 and 2). Members do not have other people take pictures of their emaciated bodies, but rather have found a method of taking such photographs in solitude. Taking pictures of oneself, as the members of the Pro-ED community do, then posting them online is paradoxical in that it is both a private and public activity. Despite the fact that they post their photos online for one another to see, they hide their emaciation from family and nonvirtual friends who are sure not to agree with their lifestyles.

The achievement of a Pro-ED collective identity requires that women promote behaviours and act in ways that allow them to navigate the people around them who are attempting to control their lives (mothers, friends, partners, etc.). They acquire the power associated with tricking people, and getting away with something that nobody wants them to achieve. Navigating these people means preventing them from gaining knowledge of their Pro-ED lifestyle. The promotion of surreptitious be- 


\section{Figure 1.}

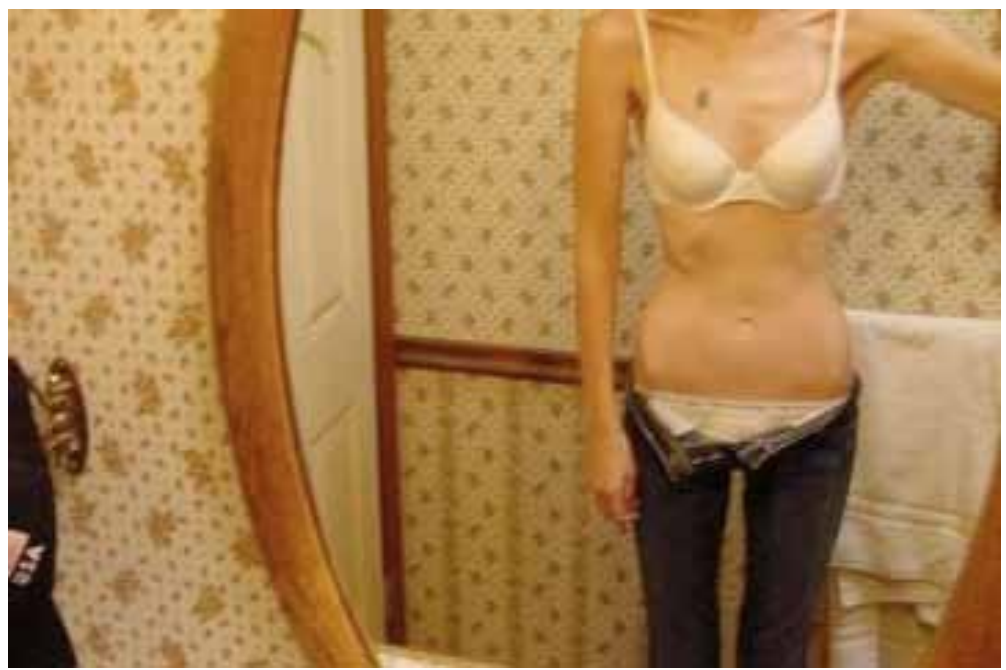

Figure 2.

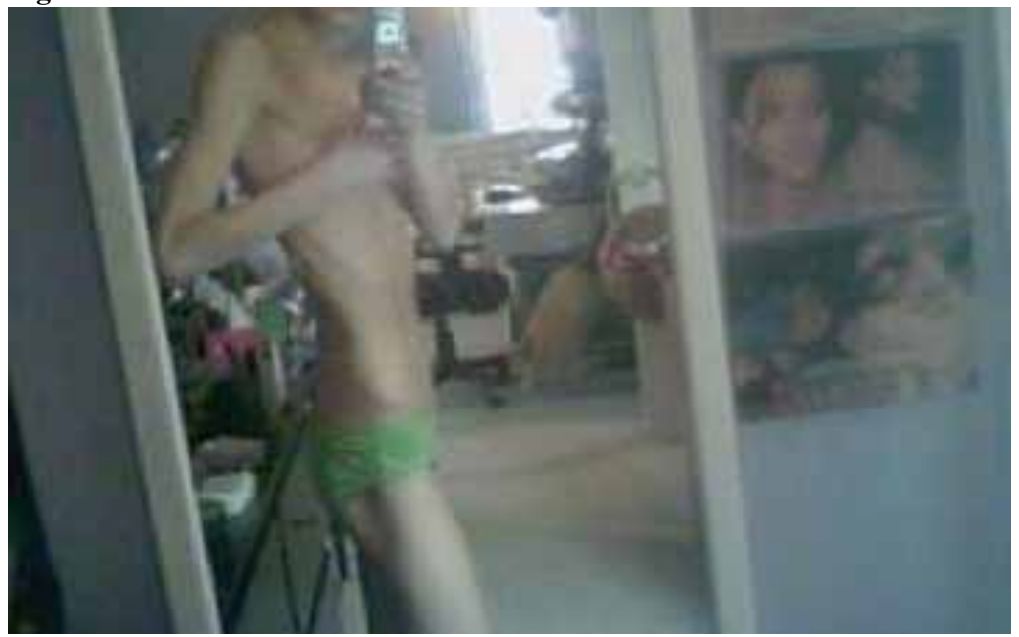

haviour facilitates the achievement of a Pro-ED identity by protecting the deviant label applied to such behaviours from people who see these women on a daily basis, and who also condemn the dangers associated with such behaviours. They accomplish a perilous identity in the face of adversity, condemnation, and disapproval. Women in the Pro-ED community wield the power of a secret by promoting disingenuous behaviours to protect their personal secret, and thus their collective identity. 
The above actions, narratives, and responses illustrate the way in which the Pro-ED community encourages the use of secretive practices in order to maintain their eating disorders, feelings of personal power, and membership in an exclusive club of other Pro-ED women. The promotion of "tips and tricks" demonstrates that not only is the Pro-ED community organizing underground, covertly, and in secretive ways by not challenging the broader social order, but they are also encouraging daily behaviours that earn them personal power through stealth. Only those involved in the Pro-ED community, true "anas, rexies and mias," 4 can know about their struggles in order to provide understanding, encouragement, and support. The support they provide one another is also gendered in that it occurs in the context of the domestic realm.

\section{Organizing around the Domestic Realm}

Despite massive gains made by women in the public sphere through large-scale labour force participation, the domestic realm and the private sphere are acknowledged as the province of women. Feminist political economists, such as Hochschild (1989), Luxton (1980), and Fox (1980), have highlighted the social inequalities that result within and outside the home, culminating in women's marginalized social position due to domestic responsibilities, and the larger social and cultural devaluation of such responsibilities. The gender ideology of women as domestic idols is prevalent and often implies that women are empowered by responsibilities such as cooking, cleaning, and other household activities.

Women's domestic "authority" is difficult to disassociate from their role as mothers and caretakers. Their relegation to the private sphere is considered natural because the domestic sphere is conceptualized as the domain of women. Women's domesticity, therefore, has become a reflection of their place as mothers in our homes, and also legitimizes their gender identity as women. Food preparation, cleaning, and care taking are three primary activities that take place in this sphere. Pro-ED adherents promote all three of these behaviours in their narratives and make use of these associations in their daily practices.

Women in the Pro-ED community exchange what they refer to as "tasty" and "yummy" recipes and recommend certain food products that help women loose weight, speed up metabolism, suppress hunger, or are purge easily. Women's concern with food is intimately connected to the assumption that they are responsible for its preparation. Feminist analyses of women and their relationship to food reveal the complicated social relations that perpetuate the role of women as both as maternal

4. Rexies, anas and mias are all underground terms used to refer to individuals in the ProED community who are anorexic and bulimic respectively. 
feeders and dieters. Kane (2002:315) argues that, "feeding is a primary part of women's role in our culture. It is a problematic but central element of femininity, and as such plays a part in the current crisis in gender roles." The perpetuation of these gender roles is observed in the Pro-ED community whereby members facilitate the achievement of an eatingdisordered lifestyle by sharing food recipes. One member recommends the following recipe because "it tastes awesome" (the numbers listed next to the ingredient indicate its caloric value):

Mander's Hawaiian Salad:

Lettuce (5)

Fat Free Italian Dressing (15)

Meatless Bacon Bits (30)

A spoonful or 2 of pineapple ( 20 cals for $1 / 8$ of a cup)

Mix together.

(PADU, December 2006)

Another recipe, is praised for being under 30 calories:

Quick Dinner under 30 Cals:

1 slice onion

1 slice green pepper

1 asparagus spear

1 egg white

Slice up onion, asparagus spear, and green pepper, you can chunk them, dice them whatever you want. Spray your frying pan with non-stick cooking spray. Add your asparagus spear, green pepper, and onion. Cook for about a minute. Add egg white and stir until fully cooked. Add salt, and pepper to season. Enjoy! (PADU, December 2006)

Another member recommends a specific ready-made pudding product because it tastes delicious and is easy to purge. She states:

Hey! This is for all mia/ana girls... if you've heard of butterscotch angel delight, the pudding... if you really wanna treat yourself, its 91 cals per serving, and absolutely delish! and easy to purge. i [sic] often treat myself to it and it fills me up.... (PADU, December 2006)

Outsiders would not likely classify these recipes and food products as actual meals since very few of them consist of any substantial amount of food, taste, calories, or nutritional value. The irony and contradiction inherent in these activities are obvious. Such practices have been normalized for these women through the achievement of a Pro-ED identity. Women in the Pro-ED community exchange these recipes in order to maintain their eating-disordered lifestyles. Moreover, these recipes are 
described as delicious and members are encouraged to enjoy the food, despite the fact that they are attempting to deprive themselves in the process. The need to care for and about the food among Pro-ED members is important, even though they go to great lengths to suppress their hunger and appetites. While depriving and starving themselves, and encouraging others to do the same, members in the Pro-ED community still feel responsible - as many women without eating disorders also do - for the food to taste good.

Organizing around the domestic realm does not stop with food preparation. Pro-ED adherents also suggest cleaning as a distraction from hunger. Repeatedly in website discussion and messages boards members ask for tips on how to help them forget their hunger. The most common reply instructs them to clean. Using cleaning as a tool of distraction reinforces the gender ideology that naturalizes women's place in the home. The connection between cleanliness and eating disorders is powerful because eating disorders themselves represent a means through which women keep their bodies clean especially from food and the corporeality of their bodies (i.e., purging). Both practices - the eating disorder itself and the habitual cleanliness - suggest an association between the material as dirty and excessive.

Finally, despite Pro-ED members' engagement in self-destructive behaviours, they continuously beg one another to be "safe" about their daily choices. One member professes her gratitude for "safe tips," stating "Thanks for the safe advice you've given me. I've felt desperate and would have taken far more dangerous methods had I not found these" (PADU, December 2006). "Safe" tips usually follow a harm reduction approach wherein members remind one another about the dangers of eating disorders while still engaging in what are considered destructive behaviours. Reminders range from stressing the importance of taking a daily multivitamin for anorexics whose routine caloric restrictions can be life-threatening, to explaining the dangers associated with brushing teeth after purging for bulimics. Some would say that the harm reduction approach in the Pro-ED community suggests that these women may be on a path to recovery. However, this approach is prevalent in all the websites, despite members' self declared stage of, or belief in, recovery. Most members declare whether they are contemplating recovery, denying recovery, believe they will never recover, or are recovering from recovery (i.e., re-entering the Pro-ED lifestyle). Notwithstanding their beliefs about recovery, members offer advice to one another that imposes a caretaking quality. Even in the context of dangerous activities in which members of the community place themselves, they promote caretaking as an imperative. Following the ideological assumption that women are 
naturally more nurturing, caretaking, and empathetic than men draws on gendered assumptions about women's domestic, motherly responsibilities.

Exchanging recipes, cleaning, and caretaking are common practices promoted in the online the Pro-ED community. These practices underscore an ideological assumption that places women in the home and limits her subjectivity to domestic responsibilities. When it comes to safety and satisfaction, Pro-ED adherents associate women with domesticity. Satisfaction, however, must be experienced in the presence of an extreme control of weight, which is emphasized in the Pro-ED community's evaluation of their self-worth through idealized standards of North American feminine beauty.

\section{Beauty as Self-worth}

The gendered character of women's preoccupation with beauty, physical appearance, and slenderness has been widely documented, especially in North America (for examples see: Chernin 1981; Brownmiller 1984; Chapkis 1986; Wolf 1990; Peiss 1998; Gimlin 2002; Cahill 2003; Chin and McConnell 2003; Black 2004). The connection between thinness and femininity is made at an early age (Pine, 2001). It has also been suggested that women's sense of their self-esteem, and by extension their self-worth, is directly related to their perceived attractiveness in physical appearance (Hesse-Biber et al. 2006). Measuring one's self-worth and self-esteem in relation to physical attractiveness is intimately connected to a history of the objectification of the female body (Bordo 1993). Obsession with physical appearance as self-worth is obvious in the Pro-ED community. Members measure their self-worth in relation to how thin, sexy, and beautiful they can become. They engage in a type of exhibitionism, typical among young women, to assert their Pro-ED identity and protect their destructive lifestyles.

Women in mainstream culture are more often the "gazed" than the "gazers" (McKinley and Hyde 1996) and are generally less satisfied with their body than males, particularly if they hold typical feminine gender beliefs (Franzoi 1995). Interestingly, however, in the context of the Pro-ED community these women have become both the "gazed" and "gazers" as they post images of themselves and use images of others as inspiration for their weight loss goals. The simultaneous positioning as "gazed upon" and "gazers" emphasizes how these women gain an authoritative subjectivity from being a part of this community.

Photographs of members, celebrities, and anonymous women who are emaciated pervade the websites. "Thinspiration" photographs are often intended to provide encouragement and inspiration to uplift the 
member's "down" mood. These photographs and videos are often posted after a member is unable to achieve a desired weight, fast for enough days, or not binge. Elise states,

I binged a little yesterday so this should be "fasting day one." But today will be a better day. I'm now 90lbs (again). So I have to get down to 85 . I need some support! i [sic] love you girls! Thinspo: (followed by photographs of emaciated women). (General Posting PADU, October 2006)

Elise, among other members, finds inspiration in the photographs of thin women, and uses them as a means to help her get past her binge behaviour. Her identity as a Pro-ED woman is demonstrated through the photographs she values of both herself and others. A common photograph featured on the websites is of women whose thighs do not touch (see Figure 3), which is a signal in the community that a member is committed to the Pro-ED lifestyle.

In posting endless images of women as inspiration, women in the Pro-ED community imply that they define their worth as individuals, and more specifically as Pro-ED women, with respect to their physical appearance, and that appearance must conform to images of emaciated women. Further, displaying emaciated images online without faces supports the notion that women, in social spaces, should be seen and not heard. That is, their purpose is for the consumption of others and they are seen as objects (Bordo 1993). Almost none of the photographs featured on the websites are accompanied by captions or descriptions, and none of them show faces. This reflects the idea that physical appearance is

\section{Figure 3.}

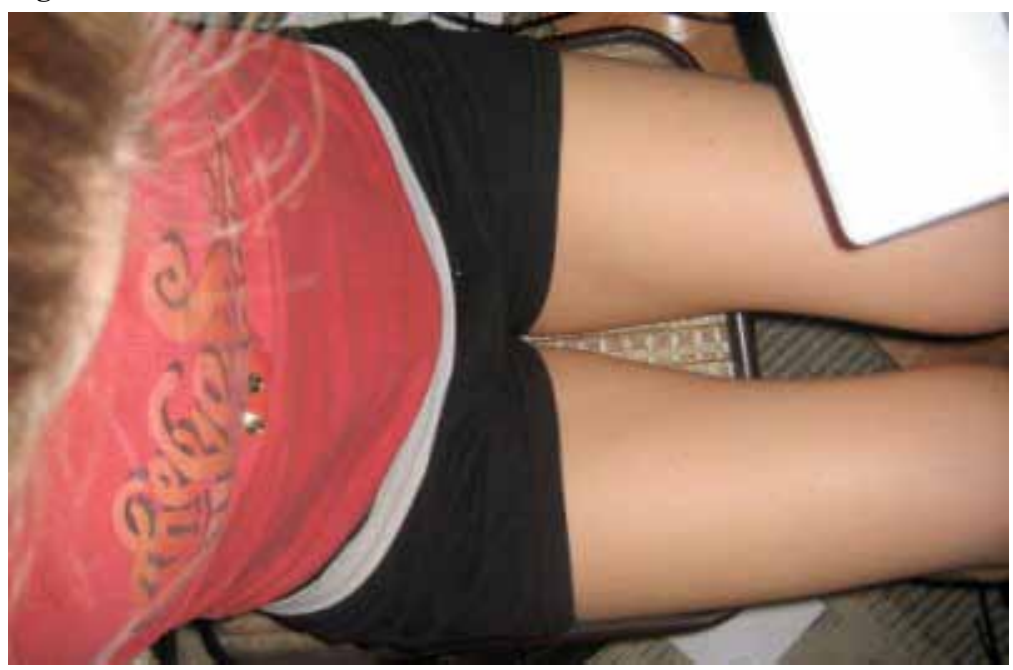


what matters most in evaluating one's self-worth. Members epitomize their Pro-ED identity by posting photographs that document their starvation and emaciation.

In addition to posting photographs, women in the Pro-ED community reinforce the notion of women as objects through their obsession with beauty rituals connected to fashion and make-up as discussed through their online postings. An overall obsession with beauty and physical appearance prevails in the Pro-ED community. In a website posting linked to PADU, one member devotes an entire section of her website to providing tips on "How to look like a model." She states: "Mind your style, from top to bottom. There are two things that can make or break your look: your hair and your shoes" (Personal homepage linked to PADU, November 2006). Further she stresses the importance of smiling:

Smile, and do it like you mean it. Models are happy girls, even though they might look bored or fierce on the runway.... Smile, be merry and people will notice that. It will help you meet people and be talked about. (Personal homepage linked to PADU, November 2006)

Equating beauty with self-worth relies on the ideology that women's worth is judged in relation to their physical attractiveness. Attractiveness for these women follows a North American beauty standard: that is, thin and toned with immaculate hair, skin, make-up, and clothes. By drawing on the ideology of women as embodying beauty, the Pro-ED community appeals to existing and potential members with the use of practices that women and girls already believe are important for their self-worth. Asserting their Pro-ED identity with the use of such gendered practices logically follows from what they believe is important: beauty. This beauty is achieved through public recognition and celebration of ED as an achievement.

\section{Fostering Friendship: Eating Disorders as Life Long Companions}

The Pro-ED community's collective practices are not only preoccupied with beauty and appearance, but also with finding solidarity and friendship among other "anas" and "mias." In addition to the friendships they develop with other women who have eating disorders, they also characterize their eating disorders as friends. In fact, Tierney and Fox (2010) suggest that women's "bond" with their eating disorders helps explain their reluctance to recover. Most members in the Pro-ED community personify their eating disorder by assigning them shorthand nicknames such as "Ana" and "Mia," which refer to anorexia and bulimia respectively. The process of personification demonstrates how these women see themselves as having long-term relationships with their eating disorders, 
in a way that most people would commit to a friend or partner. One of PADU's site visitors discusses her relationship with anorexia. She writes, "ana and I have been friends for about a year now and she's helped me so much after having my daughter" (Guestbook, PADU December 2006). In a poem describing her relationship with anorexia another member writes: "Look over my shoulder, back ribs bulge, I smile, that made me feel better, for a while ... I have a friend, its a love/hate thing. Her name is Anorexia Nervosa, but I call her Ana" (Poems, PADU, November 2006). The reference to "Ana" and "Mia" as close friends is ubiquitous in the website postings. In one posting a member reports that

Ana loves me, She may use me, But she won't forget me. I am not her victim, I am one of her lovers. Everyday I pray to be loved above the rest. Perfect is what I need to be. Perfect one day I shall be. (Kizzy's personal homepage linked to PADU, November 2006)

These narratives illustrate the comfort the women receive from their dependence on anorexia. They demonstrate how women in the community rely on eating disorders to define their subjectivities through the unconditional love the eating disorders provide.

In addition to the friendship women develop with their eating disorders, they also foster friendships among each other. Nightly conference calls over the phone, advertised by the website, last for anywhere up to 6 hours. Chatrooms facilitate the development of friendships where women can talk to each other online about their experiences and feel that they are understood. One member expresses her gratification towards the site in stating, "Just wanted to say FINALLY I've found somewhere people understand, its like finally I can let it all out and people understand!!" (PADU, Guestbook, October 2006). Access to chatrooms and conference calls are restricted to members only.

Despite the fact that these friendships develop online with presumably no face-to-face contact, women on the site constantly repeat, through their postings, how much they love and rely on each other. Such an overt display of intimate friendship connections between "strangers" is deeply gendered in that women are able to express intimacy towards other women, while intimate male-male friendships are stigmatized, especially in the North American context. Intimate male friendships and declarations of intimacy between men are forbidden because they threaten a man's presumed heterosexual orientation and perceived masculine gender identity (Kimmel 2003). According to traditional gender scripts men are only allowed to engage in so-called intimate activities with one another, such as touching each other's bottoms and hugging, in sports settings and other settings dominated by male presence (Messner 2003). 
In the Pro-ED community, intimate friendships and declarations of love are supported. Commonly used salutation used online include: "I love you girls," "I love you all mwah," "Thanks so much for the support" (PADU, December 2006). These statements reflect a level of intimacy shared and encouraged within the Pro-ED community that display a highly feminine gender quality.

Relying on friendship, both with eating disorders and other women, as a collective practice has a particular gendered character; women have typically been associated with caring, friendship, and are usually ensconced in relationship issues. In A Different Voice, Gilligan argues that women are socialized to think and act in terms of caring and relationships, while men are expected to act and think according to rules and justice (1982). Gender scholars have drawn a great deal from her observations developing a theory pointing to the socially constructed "ethic of care" that is expected of women.

Purveyors of the sites maintain that the support they receive from one another helps inspire them to reach their weight loss goals. Many members declare the importance such friendship networks serve in providing them with inspiration and nonjudgmental support. One guest to the site says, “Ana and I haven't been close for very long so some days are very hard. I am now signing up to join you (the website). Thanks again the support here came at the best time!!!" (PADU Guestbook, October 2006). Another describes how it helps her get through difficult times, "When I am struggling, when I feel shitty, I come here, watch the pix, and then everything's OK. I really enjoy coming here, and I hope this site is gonna last forever" (PADU Guestbook, September 2006). These remarks illustrate how women in the Pro-ED community develop friendships with each other and emphasize the importance of maintaining such friendships. These friendships also combat feelings of loneliness that plague many of the members, as demonstrated by the following statement.

This is a really great place. I am astonished at the support that I've witnessed within this group. I feel a new sense of ability. I am recovering from "normal" habits and am now reembracing [sic] a "pro-mia" lifestyle. I'm just really happy to know that I am not alone. (PADU Guestbook, November 2006)

Finally, the development of the "Red Bracelet Project" solidifies the way in which members in the Pro-ED community are bold about friendship. The "Red Bracelet Project" developed in the early stages of the ProED movement where women with various eating disorders would label their eating disorder by wearing a specific coloured bracelet. The colours 
for each disorder varies, wearing red represents having anorexia nervosa and purple represents bulimia nervosa. The project echoes a feminized culture of friendship whereby girls have been known to exchange friendship bracelets as a display of their solidarity and companionship.

The gendered nature of the friendship practices in the Pro-ED community rely on the ideology that women are naturally invested in personal relationships and would thus be attracted to a collective identity that uses such enticing tactics. It seems Pro-ED members are interested in gaining friends, solidarity, and wearing jewelry to display their identity. The identity of the Pro-ED community can be epitomized as a group of women exchanging jewelry, chatting about their lives, and discussing their problems.

\section{Pro-ED Celebrity Icons}

The Pro-ED community's fascination with celebrities is widespread online. The gendered character of feminine identification with celebrity personalities has been widely documented (Harrington and Bielby 1995; Scodari 2005; Gregson 2005; Mazzarella 2005). Most members have pictures of celebrities who have struggled with eating disorders (Nicole Ritchie, Mary-Kate and Ashley Olson, Paris Hilton) on their homepages. These celebrities are seen as icons and for many members represent strength and inspiration. One visitor exclaims, "My Idol is NICOLE RICHIE because she has such willpower. I also idolize MK OLSON and KATE MOSS. VICTORIA BECKHAM also because her waist is SuperSmall” (PADU, Guestbook, December 2006). "Thinsipiration” generally features a compilation of extremely thin celebrities to inspire women in the Pro-ED community to lose weight or reach their goal weight attached to comments such as: "Thin is In." Moreover, PADU features links to "Sister Sites" which are all websites of celebrities (Mary-Kate Olson, Nicole Ritchie, Keira Knightly, Gemma Ward, and Lindsay Lohan).

In the Pro-ED community, reliance on thin celebrities for inspiration also extends to a deep fascination with models. One member stresses the importance of looking like a model and the allure it carries while providing tips on how to achieve this look. She writes:

Looking like a model involves more than just pouting and strutting your stuff. Models have a confident mystique about them. Even the most unconventionally beautiful models carry themselves with an aura that exudes style, grace, and health. (website linked to PADU, November 2006)

A "type" of look is valorized in the Pro-ED community through idolizing extremely thin celebrities and models. The valorization of this look stems from the idea that women's self-worth and self-esteem is directly 
related to their physical attractiveness. Measuring women according to external, unattainable beauty standards is a gendered phenomenon and treats them as objects. It has been argued that the sexual objectification of women in media culture affects women more than men (Kilbourne 2000).

\section{Discussion And Conclusion}

Despite widespread resistance towards their activities, proclamations, and beliefs (i.e., shutting down their websites, initiating censorship debates, denouncement of their practices in the mainstream media, and receiving "hate email" among others) the Pro-ED community has become prolific, successful, and consequential to the everyday lives of many women living with eating disorders. I suggest that gender is one of the mechanisms by which this success is achieved. A stigmatized group of women have effectively come together around an identity, engaging in eating-disordered practices that the majority of people wish they would seek help for. In spite of mainstream prescriptions to recover, women in the Pro-ED community have cultivated a collective identity, and preserved a set of damaging behaviours with the use of organizing strategies that conform to specific feminine ideals.

It is possible that the women in the Pro-ED community find the resistance towards their activities motivational. Perhaps it provides them with access to a rebellious self that is also productive towards the achievement of Pro-ED identity. This speculation is one that should be pursued in further research. To what extent does being seen as disaffected and obstinate fuel their actions? Do they embrace this perception? How might it contribute to their practices?"

The five gendered tactics analyzed herein reinforce, reinscribe, and reproduce exaggerated versions of feminine gender identity based on larger gender prescriptions and the acceptance of dominant gender norms. Beyond telling us that women in the Pro-ED community successfully "do gender" (West and Zimmerman 1987), this case study also demonstrates how gender serves as a justifying and legitimating framework upon which these women build a meaningful, yet destructive, identity. The Pro-ED community has become prolific, successful, and well known, even in the face of much resistance and opposition. This success, as demonstrated here, may well be the result of the gendered practices members employ online. Eating disorders are, in part, a product of gender ideologies, so it makes sense that a group of women, who support the maintenance of eating disorders, draw on gendered practices to achieve a collective identity. 
Popular sociological understandings of collective identity organizing rely on the assumption that collective identity cultivation and its outcomes have beneficial results for its members through liberation or social change. However, the case study presented here shows that this quixotic and idealistic version of collective mobilization is not always true. Analyzing the gendered character of Pro-ED groups' online activities illustrates how a stigmatized group of women makes use of mainstream gender ideologies and activities to support a life mostly portrayed as exceptionally deviant and destructive. The use of such gendered practices is especially interesting to consider since it has been acknowledged that eating disorders are a rejection of the female body and its feminine characteristics such as breasts, hips, and thighs. What then is the connection between the embodiment of femininity and collective identity practices? Is there a connection?

In destabilizing common understandings of collective identity mobilization as categorically beneficial for its members we are forced to ask new questions about collective identity organizing and gender. We can see, through this case study, that gender is used as a justificatory framework for deviant and destructive behaviours, but we cannot assume that this is true in all contexts. Do other groups who cultivate collective identity for nonliberatory purposes use gender in a similar legitimating fashion? Does gender operate in the same or different ways when the outcome of collective organizing is not liberation or social change? How does the construction of collective identity compare in communities or movements that are sustained by activist agendas (i.e., gay rights, women's rights, environmentalism) vs. those maintained by behaviour and/or identities? How might men, in similar online contexts, cultivate collective identity around a lifestyle choice? Answering these questions will help push forward our understanding of collective identity organizing, gender, and social movement behaviour.

Finally, a central irony is evident in Pro-ED community organizing wherein women conform to dominant gender scripts in order to subvert dominant prescriptions for healthy living. This irony suggests that a tension exists between what is required to be healthy and what is required for womanhood, which future studies in this area need to pursue. Pursuing this line of inquiry requires that we speak directly to women in the Pro-ED community about their conceptualization of gender and femininity. Doing so will help us better understand how they reconcile and negotiate the tension between gender ideals and their "safe" eating-disordered lives. 


\section{REFERENCES}

Abbate Daga, G., C. Gramaglia, A. Piero, and S. Fassino. 2006. Eating disorders and the Internet: Cure and curse. Eating and Weight Disorders 11(2):6871 .

Allred, Sarah. 2009. Reframing Asperger syndrome: Lessons from other challenges to the diagnostic and statistical manual and ICIDH approaches. Disability \& Society 24:343-355.

Armstrong, Elizabeth. 2002. Forging Gay Identities: Organizing Sexuality in San Francisco, 1950-1994. Chicago: University of Chicago Press.

Bernstein, Mary. 1997. Celebration and suppression: The strategic uses of identity by the lesbian and gay movement. American Journal of Sociology 103:531-65.

Black, Paula. 2004. The Beauty Industry: Gender, Culture, Pleasure. New York: Routledge.

Bordo, S. 1993. Unbearable Weight: Feminism, Western Culture and the Body. Berkeley: University of California Press.

Brown, Lyn Mikel. 2003. Girlfighting: Betrayal and Rejection Among Girls. New York: New York University Press.

Brownmiller, Susan. 1984. Femininity. New York: Linden Press.

Cahill, Ann J. 2003. Feminist pleasure and feminine beautification. Hypatia $18(4): 42-64$.

Canadian Institutes of Health Research, Natural Sciences and Engineering Research Council of Canada, Social Sciences and Humanities Research Council of Canada. 1998. Tri-Council Policy Statement: Ethical Conduct for Research Involving Humans. (with 2000, 2002 and 2005 amendments).

Chapkis, Wendy. 1986. Beauty Secrets: Women and the Politics of Appearance. Boston: South End Press.

Chernin, Kim. 1981. The Obsession: Reflections on the Tyranny of Slenderness. New York: Harper \& Row Publishers.

Chin, Peggy Evans and Allen R. McConnell. 2003. Do racial minorities respond in the same way to mainstream beauty standards? Social comparison processes in Asian, Black and White women. Self and Identity 2:153-167.

Day, Katy and Tammy Keys. 2008. Starving in cyberspace: A discourse analysis of pro-eating-disorder websites. Journal of Gender Studies 17(1):1-15.

Depowski, Kristen and Kelly Hart. 2006. 'Pro-ana' websites glorify eating disorders: Sites say anorexia isn't a disease but a lifestyle choice. $A B C$ News Health online, http://abcnews.go.com/Health/story?id=2068728\&page=1 (accessed February 22, 2007).

Dias, Karen. 2003. The ana sanctuary: Women's pro-anorexia narratives in cyberspace. Journal of International Women's Studies 4(2):31-45. 
Eaton, Kristi. 2006. The skinny on pro-ana. Current Magazine Online, http:// www.msnbc.msn.com/id/15734955/site/newsweek (accessed February 22, 2007).

Epstein, Debbie, Richard Johnson, and Deborah Lynn Steinberg. 2000. Twice told tales: Transformation, recuperation and emergence in the age of consent debates 1998. Sexualities 3(1):5-30.

Ferree, Myra Marx and David Merrill. 2000. Hot movements, cold cognition: Thinking about social movements in gendered frames. Contemporary Sociology 2(9):454-462.

Fonow, Mary Margaret. 1998. Protest engendered: The participation of women steelworkers in Wheeling-Pittsburg steel strike of 1985. Gender and Society 12(6):710-728.

Fox, Bonnie. 1980. Hidden in the Household: Women and their Domestic Labour under Capitalism. Toronto: Women's Press.

Fox, Nick, Katie Ward, and Alan O'Rourke. 2005. Pro-anorexia, weight-loss drugs and the internet: An 'anti-recovery' explanatory model of anorexia. Sociology of Health \& Illness 27(7):944-971.

Franzoi, Stephen L. 1995. The body-as-object versus the body-as-process: Gender differences and gender considerations. Sex Roles 33(5-6):417438.

Gamson, Joshua. 1997. Messages of exclusion: Gender, movements and symbolic boundaries. Gender \& Society: 11(2):178-199.

Gilligan, Carol. [1982] 1993. In a Different Voice. Cambridge: Harvard University Press.

Gimlin, L. Debra. 2002. Body Work: Beauty and Self-image in American Culture. Berkeley: University of California Press.

Glaser, Barney G. and Anselm L. Strauss. 1967. The Discovery of Grounded Theory: Strategies for Qualitative Research. Chicago: Aldine.

Goodwin, Jeff and Ruth Horowitz. 2002. Introduction: The methodological strengths and dilemmas of qualitative sociology. Qualitative Sociology $25: 33-47$.

Gregson, S. Kimberly. 2005. Girl fans of Shoujo anime and their web sites. Pp. 121-140 in Sharon R. Mazzarella, ed., Girl Wide Web: Girls, the Internet, and the Negotiation of Identity. New York: Peter Lang Publishing.

Grosz, Elizabeth. 1994. Volatile Bodies. Bloomington: Indiana University Press.

Harrington, Lee C. and Denise D. Bielby. 1995. Soap Fans: Pursuing Pleasure and Making Meaning in Everyday Life. Philadelphia: Temple University Press.

Hercus, Cheryl. 2005. Stepping Out of Line: Becoming and Being Feminist. New York: Routledge. 
Hesse-Biber, Sharlene, Patricia Leavy, Courtney E. Quinn, and Julia Zoino. 2006. The mass marketing of disordered eating and eating disorders: The social psychology of women, thinness and culture. Women's Studies International Forum 29:208-224.

Hine, Christine. 2000. Virtual Ethnography. London: Sage.

Hochschild, Arlie. 1989. The Second Shift: Working Parents and the Revolution at Home. New York: Penguin Books.

Hunt, Scott A. and Robert D. Benford. 2004. Collective identity, solidarity, and commitment. Pp. 433-457 in David A. Snow, Sarah A. Soule, and Hanspeter Kriesi, eds., The Blackwell Companion to Social Movements. Malden, MA: Blackwell Publishing.

Kane, Kate. 2002. Who deserves a break today? Fast food, cultural rituals, and women's place. Pp. 315-321 in Carole Counihan, ed., Food in the USA: A Reader. New York: Routledge.

Kenny, Lorraine Delia. 2000. Daughters of Suburbia: Growing Up White, Middle Class, and Female. New Brunswick, NJ: Rutgers University Press.

Kilbourne, Jean. 2000. Killing Us Softly 3: Advertising's Image of Women. Produced and directed by Sut Jhally, 34 Minutes, Media Education Foundation: DVD.

Kimmel, Michael. 2003. Masculinity as homophobia. Pp. 103-109 in Estelle Disch, ed., Reconstructing Gender: A Multicultural Anthology. 3rd edition. New York: McGraw-Hill.

Lieberson, Stanley. 1992. Small n's and big conclusions: An examination of the reasoning in comparative studies based on a small number of cases. Pp. 103-118 in Charles Ragin and Howard Becker, eds., What is a Case? Exploring the Foundations of Social Inquiry. Cambridge: Cambridge University Press.

Luxton, Meg. 1980. More than a Labour of Love: Three Generations of Women's Work in the Home. Toronto: Women's Press.

Mann, C. and F. Stewart. 2000. Internet Communication and Qualitative Research: A Handbook for Researching Online. London: Sage University Press.

Mazzarella, R. Sharon. 2005. The cultural economy of teen girl fandom on the web. Pp. 141-160 in Sharon R. Mazzarella, ed., Girl Wide Web: Girls, the Internet, and the Negotiation of Identity. New York: Peter Lang Publishing.

McAdam, Doug. 1992. Gender as a mediatory of the activist experience: The case of freedom summer. American Journal of Sociology 97(5):12111240 .

McKinley, Nita Mary and Janet Shibley Hyde. 1996. The objectified body consciousness scale: Development and validation. Psychology of Women Quarterly 20(2):181-215. 
Melucci, Alberto. 1995. The process of collective identity. Pp. 41-63 in H. Johnston and Bert Klandermans, eds., Social Movements and Culture. New York: Routledge.

Messner, Michael. 2003. Boyhood, organized sports, and the construction of masculinities. Pp. 110-126 in Estelle Disch, ed., Reconstructing Gender: A Multicultural Anthology. 3rd edition. New York: McGraw-Hill.

Norris, Mark L., Katherine M. Boydell, Leora Pinhas, and Debra Katzman. 2006. Ana and the Internet: A review of pro-anorexia websites. International Journal of Eating Disorders 39(6):443-447.

Peiss, Kath. 1998. Hope in a Jar: The Making of America's Beauty Culture. New York: Henry Holt and Company Inc.

Pine, Karen J. 2001. Children's perception of body shape: A thinness bias in preadolescent girls and associations with femininity. Clinical Child Psychology and Psychiatry 6(4):519-536.

Plummer, Ken. 1995. Telling Sexual Stories. New York: Routledge.

Polletta, Francesca and James Jasper. 2001. Collective identity and social movements. Annual Review of Sociology 27:283-305.

Scodari, Christine. 2005. "Fangirls" and the negotiation of age and/or gender subjectivities in TV newsgroups. Pp. 105-120 in Sharon R. Mazzarella, ed., Girl Wide Web: Girls, the Internet, and the Negotiation of Identity. New York: Peter Lang Publishing.

Simmons, Rachel. 2002. Odd Girl Out: The Hidden Culture of Aggression in Girls. New York: Harcourt.

Stacey, Judith. 1998. Brave New Families: Stories of Domestic Upheaval in LateTwentieth-Century America. Berkeley: University of California Press.

Stake, Robert E. 1994. Case studies. Pp. 236-247 in N.K. Denzin and Y.S. Lincoln, eds., Handbook of Qualitative Research. Thousand Oaks, CA: Sage.

Strauss, Anselm and Juliet Corbin. 1998. Basics of Qualitative Research: Techniques and Procedures for Developing Grounded Theory. 2nd edition. London: Sage.

Taylor, Verta. 1996. Rock-a-By Baby: Feminism, Self-Help, and Postpartum Depression. New York: Routledge.

Taylor, Verta and Nancy Whittier. 1992. Collective identity in social movement communities: Lesbian feminist mobilization. Pp. 104-129 in Alan D. Morris and Carol M. Mueller, eds., Frontiers In Social Movement Theory. New Haven, CT: Yale University Press.

Tierney, Stephanie. 2006. The dangers and draw of online communication: Proanorexia websites and their implications for users, practitioners, and researchers. Eating Disorders 14:181-190.

Tierney, S. and J.R Fox. 2010. Living with the 'anorexic voice': a thematic analysis. Psychology and Psychotherapy: Theory, Research and Practice. 
Walton, John. 1992. Making the theoretical case. Pp. 121-138 in C. Ragin and H. Becker, eds., What is a Case? Exploring the Foundations of Social Inquiry. Cambridge: Cambridge University Press.

West, Candace and Don H. Zimmerman. 1987. Doing gender. Gender \& Society 1(2):125-151.

Wolf, Naomi. 1990. The Beauty Myth, Toronto: Random House.

Krista L. Whitehead is currently a PhD Candidate in sociology at the University of Toronto. Her doctoral research examines the production of gender and the body through an exploration of women's corporeal negotiations of two embodied gender norms — beauty and motherhood. Her theoretical and academic interests include qualitative methods, sociology of gender and sexuality, the body, social movements and collective identity.

krista.whitehead@utoronto.ca 